\title{
In-Hospital Falls at the Department of Otorhinolaryngology
}

\author{
Toshiya Kimura ${ }^{1}$ Makoto Miura ${ }^{1}$ Kumiko Gyo ${ }^{1}$ Koichiro Yamada ${ }^{1}$ Keigo Honda ${ }^{1}$ \\ Yasuyuki Hayashi $^{1,2}$ Yuki Tanigami ${ }^{1}$ Mai Nakahira ${ }^{1}$ Hiroki Ikeda ${ }^{1,3}$ \\ ${ }^{1}$ Department of Otorhinolaryngology, Japanese Red Cross Wakayama \\ Medical Center, Wakayama Prefecture, Japan \\ 2 Department of Otorhinolaryngology and Head and Neck Surgery, \\ Graduate School of Medicine and Faculty of Medicine, Kyoto \\ University, Kyoto, Japan \\ ${ }^{3}$ Ikeda ENT Clinic, Tokyo, Japan \\ Int J Pract Otolaryngol 2018;1:e16-e22. \\ Address for correspondence Toshiya Kimura, MD, Department of \\ Otorhinolaryngology, Japanese Red Cross Wakayama Medical Center, \\ 4-20 Komatsubara-dori, Wakayama-shi, Wakayama Prefecture, Japan \\ 640-8558 (e-mail: t_kimura@ent.kuhp.kyoto-u.ac.jp).
}

\begin{abstract}
Keywords

- incident reports

- risk factors for fall

- hospitalization days

- older age

- malignancy

A fall accident is an event that is associated with many disadvantages. In our hospital, 5,259 fall cases have been reported over the past 7 years according to our incident reports, and account for $16.5 \%$ of all incident reports. We conducted a detailed examination of 120 of these fall cases at the Department of Otolaryngology. Most of all, "before and after excretion" is a common fall-outbreak-motive reason for falls in all departments. In the field of otolaryngology, "use of drugs" and "walking disorder" are frequently encountered reasons for a fall. Calculation of age-specific fall rates revealed two peaks: around 0 years old and after 80 years old. It is suggested that a fall is associated with a reduced ability for maintaining the standing position. A correlation has been reported between the fall rate and the average length of hospitalization. Both the length of hospitalization of 12.3 days and fall rate of 1.97 among the cases seen at the Department of Otolaryngology are lower than all courses that are in other fields, on average. In the patients seen at the Department of Otolaryngology, the fall rate rises significantly as the length of hospitalization increases. In the Department of Otolaryngology, the fall rate of the malignancy group is high (2.91), irrespective of the treatment regimens. Each of the three items-"14 hospitalization days or more," "65 years old or older," and "malignancy"-contributes to falls in patients seen at the Department of Otolaryngology, and multivariate analysis revealed a particularly strong contribution of the previous two items. In elderly patients with expected long-term hospitalization, it is necessary to proactively attempt risk reduction; we first make all patients aware of the risk of long-term hospitalization at the first examination, and divide length of stay into multiple times. We review the assessment score after reexamining the "disease severity" and "performance status" as risk factors for falls, and want to realize more efficient measures for preventing falls in the future.
\end{abstract}

\section{Introduction}

Fall accidents that occur within the hospital are a serious issue because they not only affect patient treatment outcomes but also health economics. At our hospital, there were 132,041 hospitalizations in all departments between December 2009 and November 2016, and a total of 31,775 incidents and accidents were reported during this 7-year period. Of these, received

May 28, 2018

accepted

August 13, 2018
DOI https://doi.org/

10.1055/s-0038-1675405. ISSN 2569-1783.
Copyright @ 2018 Georg Thieme Verlag KG Stuttgart · New York
License terms

(๑) $\Theta \circledast$ 
the number of accidental falls was 5,259, accounting for $16.5 \%$ of all incidents/accidents. Because accidental falls are always one of the most frequent incidents in hospitals, it is important to implement countermeasures to prevent the worsening of patient prognosis and decrease the additional testing and treatment required due to incidents. In this study, we investigated fall risks according to onset mechanism, background, sex, age, and duration of hospital stay and examined the diseases and treatments for patients hospitalized in the Department of Otorhinolaryngology.

\section{Patients and Methods}

There were 4,960 hospitalizations in the Department of Otorhinolaryngology at the Japanese Red Cross Wakayama Medical Center over the 7-year period between December 2009 and November 2016. During this period, there were 120 fall accidents reported. We compared these numbers with the total number of falls in all departments $(5,259)$ over the same period. Data for all departments were obtained from the incident and accident reports, while data from the Department of Otorhinolaryngology was gathered from the incident and accident reports and from discharge summaries for all inpatients.

In this report, "falls by slips or trips" and "falling down" are collectively referred to as "falls."

Parameters including sex, age, duration of hospital stay (all departments/Department of Otorhinolaryngology), and the presence of malignant diseases (Department of Otorhinolaryngology only) are also used in the Ministry of Health, Labor, and Welfare Patient Survey and for internal statistics at our hospital. These parameters are easy for data collection and are valuable as epidemiological data. In this report, we used the fall rate ${ }^{1}$ [(number of fall incidents/total hospitalization days $) \times 1,000$ ] as an indicator of fall frequency. Fall rate was effective for grasping epidemiological trends because it reflects overall patient population rather than an individual patient. A comparative analysis on these data was performed using the chi-square test.

Otorhinolaryngological diseases were classified based on the disease name on discharge, and disease groups were created as follows: malignant, ear, nose, and other benign diseases. The fall rates were compared between the four disease groups using the Fisher exact test and the Benjamini-Hochberg procedure.

Fall rates were also compared using the chi-square test depending on whether treatment for malignant diseases was performed.

Statistical analysis was performed based on the comparison of fall rate. When comparing risk factors for falls, "whether a fall occurred during one hospitalization" was used as a parameter. The Fisher exact test was used for univariate analysis and logistic regression method for multivariate analysis.

\section{Results}

\section{Mechanisms of Falls}

-Fig. 1 shows the action being performed when the fall occurred. Among incidents in all departments and the
Department of Otorhinolaryngology, falls occur most commonly before or after excretion. Excretion-related incidents alone accounted for approximately $40 \%$.

\section{Underlying Mental and Physical State during Falls}

-Fig. 2 shows underlying mental and physical disorders during the fall. While "dementia/amnesia" and "gait disturbance" were most common for incidents in all departments, "under the influence of medication" and "gait disturbance" were common for those in the Department of Otorhinolaryngology.

\section{Fall Rates According to Sex (-Fig. 3)}

While male patients were found to be significantly more likely to suffer a fall in all departments $(p<0.0001)$, no marked differences were noted in the Department of Otorhinolaryngology cases $(p=0.58)$.

\section{Fall Rates According to Age}

-Fig. 4 shows fall rates for all departments and for the Department of Otorhinolaryngology. Both were bimodal, exhibiting peaks at around 0 years and after 80 years of age. In all department cases, the data approximated a cubic function, and for Department of Otorhinolaryngology cases, the data approximated a quadratic function. The lowest value was in the 30 s.

\section{Fall Rate and Duration of Hospital Stay}

Fall Rate by Department and Mean Length of Hospital Stay (-Fig. 5)

The relationship between fall rate and duration of hospital stay was shown using fall rate according to department and mean length of hospital stay for a simplified view. A correlation was observed between fall rate by department and mean hospital stay (days; correlation coefficient $R^{2}=0.2809$ ). Moreover, fall rate in the Department of Otorhinolaryngology (1.97) was significantly lower than that in all departments $(2.98 ; p<0.0001)$, and the Department of Otorhinolaryngology's mean hospital stay (12.3 days) was significantly shorter than that of all departments (13.5 days; $p<0.0001)$.

\section{Hospital Stay and Fall Rate in the Department of Otorhinolaryngology}

-Fig. 6 shows fall rates until day X among Department of Otorhinolaryngology inpatients. There is a peak soon after hospitalization (day 4), and the rate is lowest on day 9 of hospitalization. Subsequently, the fall rate becomes higher as the hospital stay becomes longer.

\section{Fall Rates According to Otorhinolaryngological Disease}

Otorhinolaryngological diseases were divided into four groups (malignant, ear, nose, and other benign diseases; - Table 1). Comparison of fall rates among these groups revealed that the fall rate was significantly higher in the malignant disease group (2.91) than in ear and other benign disease groups. 


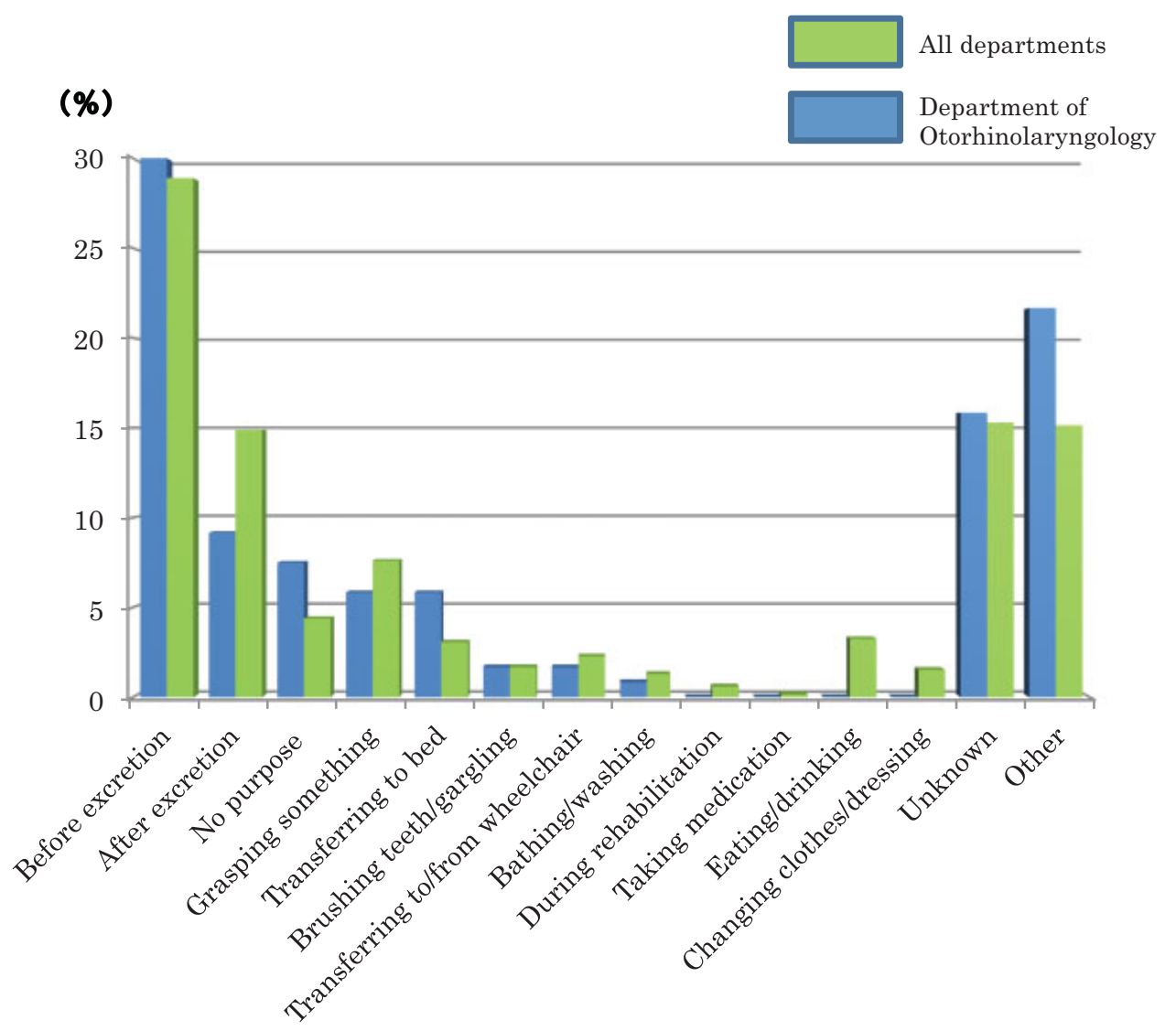

Fig. 1 Fall-onset mechanisms before and after excretion were common for both all departments and the Department of Otorhinolaryngology.

\section{Fall Rates by Treatment for Malignant Diseases at the Department of Otorhinolaryngology}

We compared fall rates for malignant diseases in the Department of Otorhinolaryngology (1,036 cases) according to whether surgical treatment, chemotherapy, or radiotherapy was performed (-Table 2 ). No statistically significant differences were noted.

\section{Analysis of Fall Risk Factors (- Tables 3 and 4)}

Age, male, malignant disease, and days of hospital stay increased the fall rate in all departments or the Department of Otorhinolaryngology. Thus, all four parameters appear to be candidates for fall risk factor.

Therefore, we analyzed fall risk factors for cases in the Department of Otorhinolaryngology using "whether a fall occurred during one hospitalization" as an index.

As the ROC curve's highest values for age and days of hospital stay were 64 years and 16 days, respectively, to simplify the analysis, we analyzed the following four factors: whether the age was $\geq 65$ years, whether hospital stay was $\geq 14$ days, whether the sex was male, and whether the disease was malignant.

Univariate analysis indicated that age $\geq 65$ years, presence of malignant diseases, and a hospital stay of $\geq 14$ days resulted in significantly higher rate of falls.

Multivariate analysis indicated that age $\geq 65$ years and a hospital stay of $\geq 14$ days resulted in significantly higher rates of falls.

\section{Discussion}

Several falls are reported by incident and accident reports in our hospital, and the number is also high in the Department of Otorhinolaryngology. These fall cases not only disturb smooth work operations but also cause many disadvantages, such as additional treatment for injuries, discontinuation of treatment of the main disease, and prolonged hospital stays. At our hospital, fall risk is currently evaluated using fall assessment score at the time of hospitalization and incidence of a fall. However, there are opinions that the results of such assessments differ from actual fall trends and risks. The actual state of falls needs to be determined in more detail for more efficient fall countermeasures. Therefore, we collected and analyzed data based on incident reports and discharge summaries. First, the reasons why there are many falls before and after excretion are that it requires multiple actions of activities of daily living (ADL), such as standing, sitting, walking, and transferring ${ }^{2}$; and that many patients do not wish to be assisted due to their self-respect. ${ }^{3}$

Next, medication was found to be the top underlying factor associated with falls in the Department of Otorhinolaryngology. Medication use is not significantly more common in the Department of Otorhinolaryngology than in other departments, possibly due to a relatively high use of sleeping pills. In the literature, medication such as sleeping pills, psychotropic drugs, and antihypertensives are listed as fall factors. $^{4,5}$ 


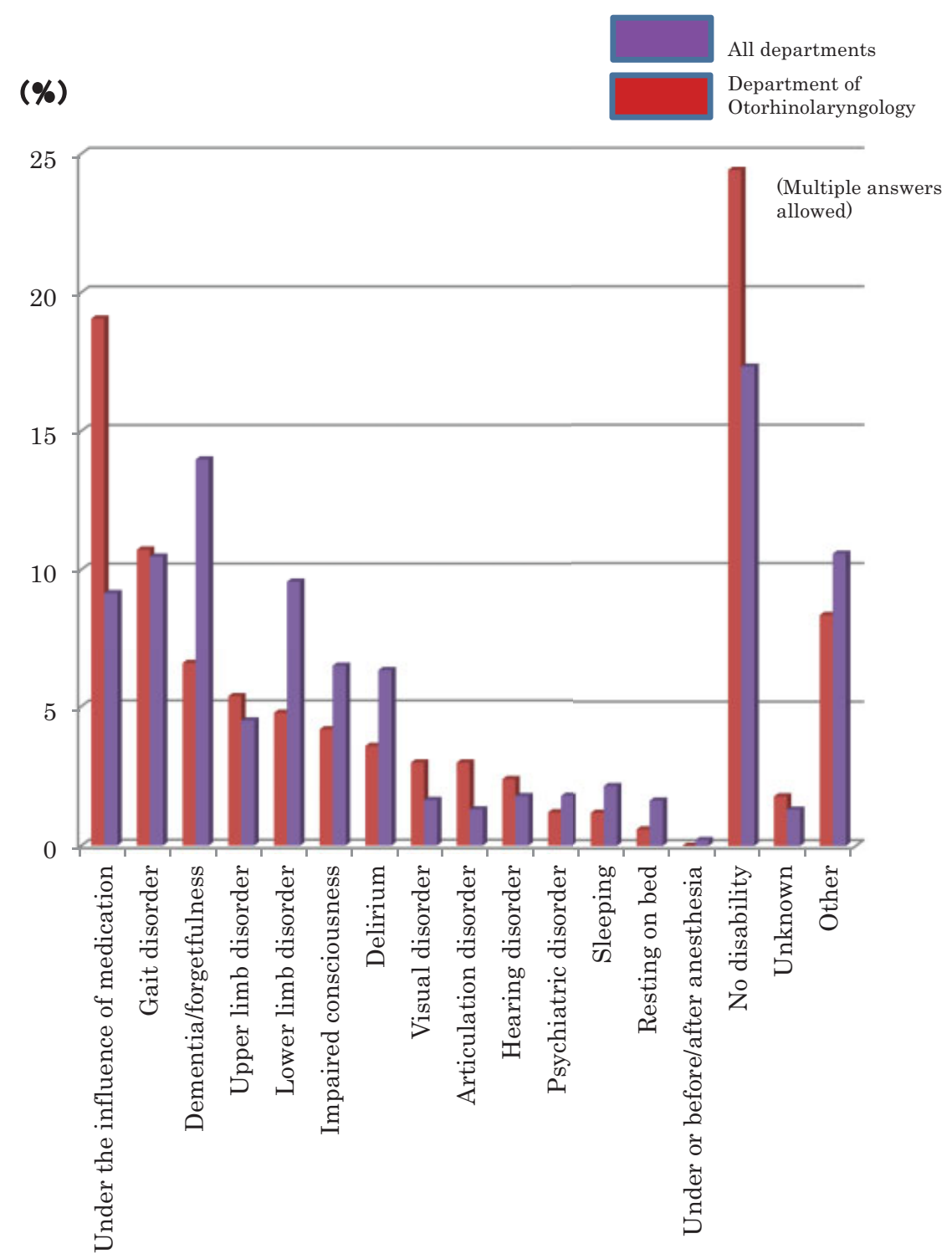

Fig. 2 Underlying mental and physical state when a fall occurred (all departments, Department of Otorhinolaryngology). In all departments, the common status was as follows: dementia/amnesia, gait disturbance, and the influence of medication, in order of frequency. In the Department of Otorhinolaryngology, the common status was the influence of medication, gait disturbance, and dementia/forgetfulness, in order of frequency (multiple answers allowed). It appears that in the Department of Otorhinolaryngology, dementia has little effect and influence by sleeping pills is relatively common.

While fall rate is generally higher in women than in men, ${ }^{6-8}$ it was found to be higher in male patients in our hospital. There have also been reports of hospitals with a higher fall rate for male patients. ${ }^{3}$ The low fall rate in female patients in our hospital is due to the low mean age of female inpatients admitted (-Table 5). Moreover, there was no difference between fall rates in male and female patients in the Department of Otorhinolaryngology because there was no difference in the mean age of male and female patients.

Next, when the fall rate was shown in a graph format according to age, a bimodal curve was seen for both all departments and the Department of Otorhinolaryngology. For all departments, the data approximated a cubic function, and for the Department of Otorhinolaryngology, the data approximated a quadratic function. This was because the male fall rate approximated a quadratic function and the female fall rate approximated a cubic function. If there was no difference between the number of male and female inpatients, a cubic function would have been obtained, and if the number of males was high, such as that in the Department of Otorhinolaryngology, a quadratic function would have been obtained (-Table 5). Comparison of these approximation curves with a curve for one-legged standing time by age ${ }^{9}$ revealed an inverse relationship, suggesting that decreased ability to maintain a standing position affects the propensity for falls.

In terms of hospital stay and fall rate in the Department of Otorhinolaryngology, the peak noted at day 4 after hospitalization indicated that falls occurred directly after the start of treatment. The lowest value observed on hospitalization day 9 was due to the high number of patients whose hospital stay was 9 days. The fall rate subsequently increased thereafter with prolonged hospital stay. 


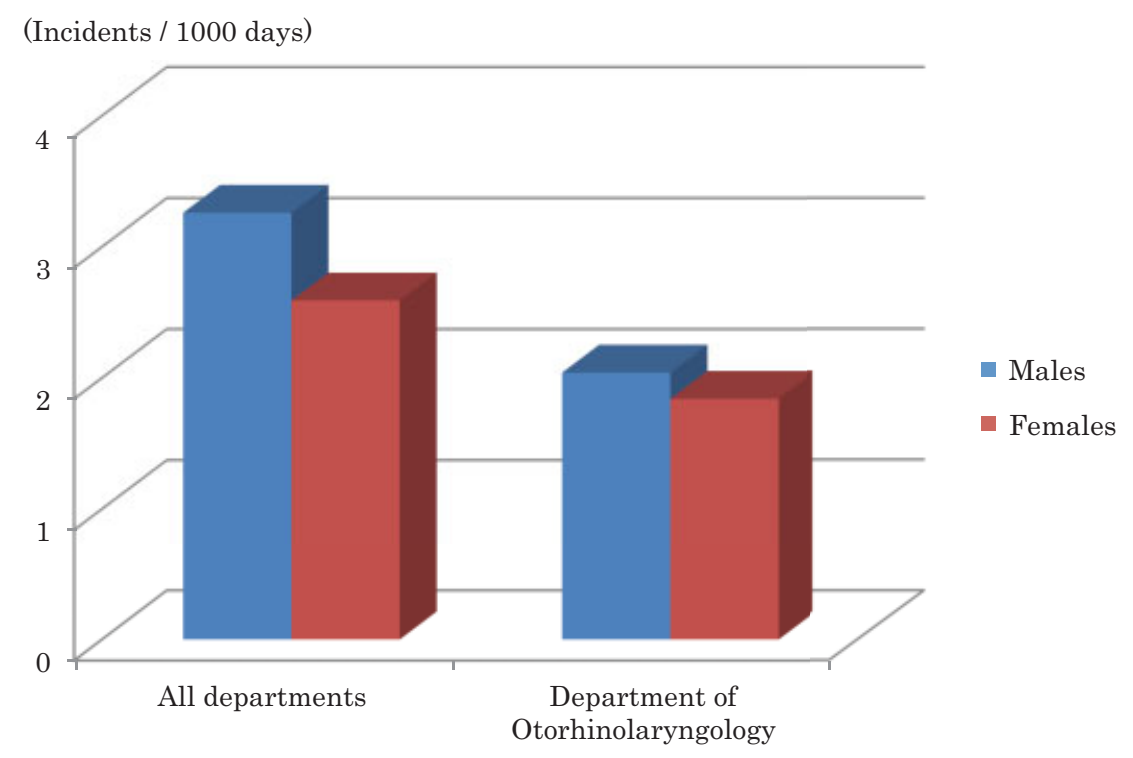

Fig. 3 Fall rates according to sex (all departments, Department of Otorhinolaryngology). While the fall rate was significantly higher among males in all departments $(p<0.0001)$, no significant difference was noted for the Department of Otorhinolaryngology $(p=0.58)$.

For all departments, male sex, age, and hospital stay appeared to be fall risk factors. The results suggested that in the Department of Otorhinolaryngology, among the four items, such as male sex, age, hospital stay, and malignant disease, the latter three were fall risk factors. Male sex, age $\geq 65$ years, malignant disease, and hospital stay of $\geq 14$ days were compared according to fall per hospitalization; it revealed that hospital stay of $\geq 14$ days was most strongly reflected in falls, followed by the influence of age $\geq 65$ years.

In terms of hospital stay, it has been reported that as an external factor, hospitalization of $\geq 19$ days is a fall risk factor. ${ }^{10}$ Fall risk increases with longer hospital stay because it is more likely to result in decrease in cognitive function, ADL, and physical function. ${ }^{11}$

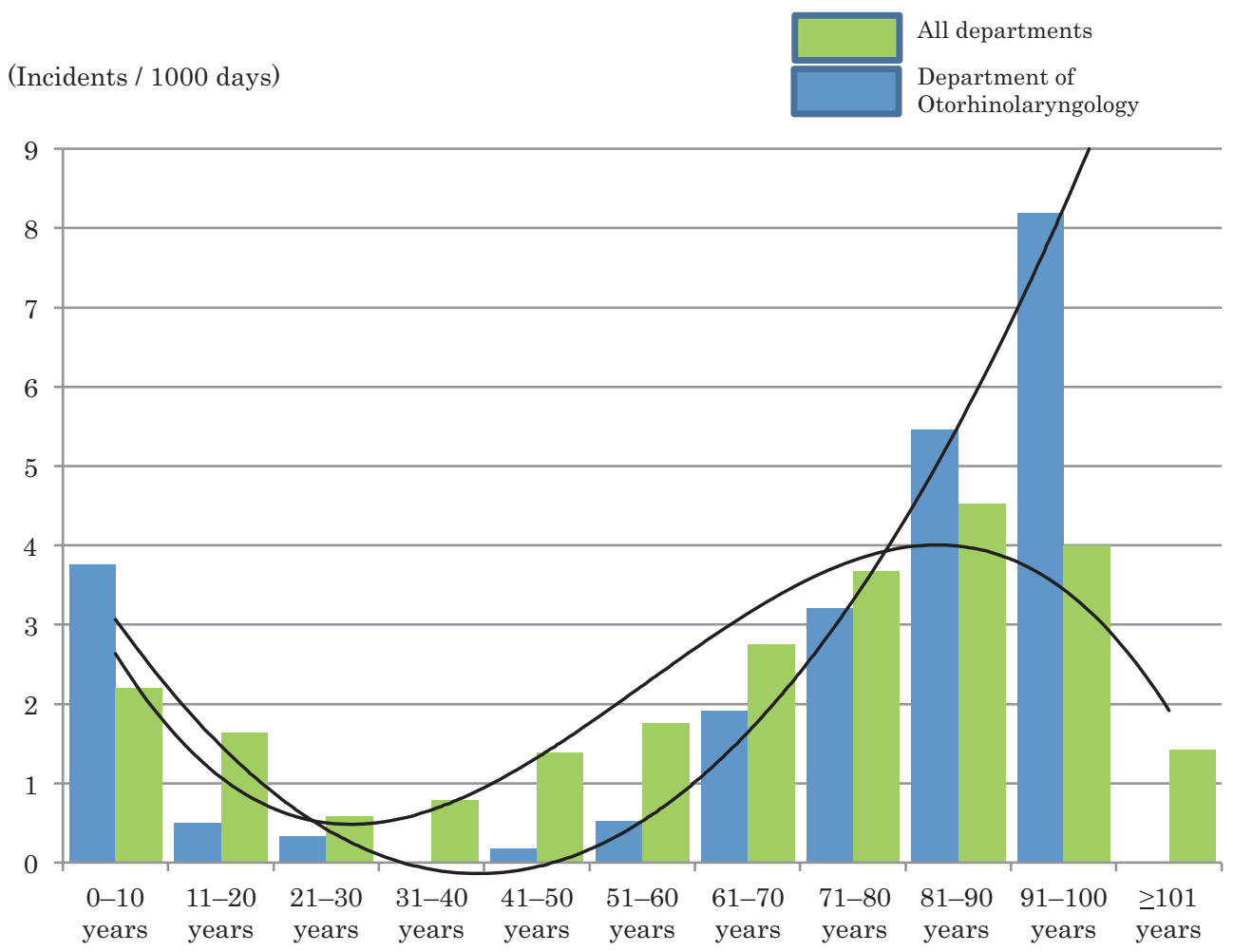

Fig. 4 Fall rates according to age (all departments, Department of Otorhinolaryngology). There were peaks at 0 years and around 80 years of age for all departments and the Department of Otorhinolaryngology. The approximation curve was a cubic function for all departments (green; $\left.y=-0.00408 x^{3}+0.7367 x^{2}-3.4821 x+5.4185 ; R^{2}=0.9001\right)$ and a quadratic function for the Department of Otorhinolaryngology (blue; $\left.y=0.2714 x^{2}-2.409 x+5.2058 ; R^{2}=0.9765\right)$. 


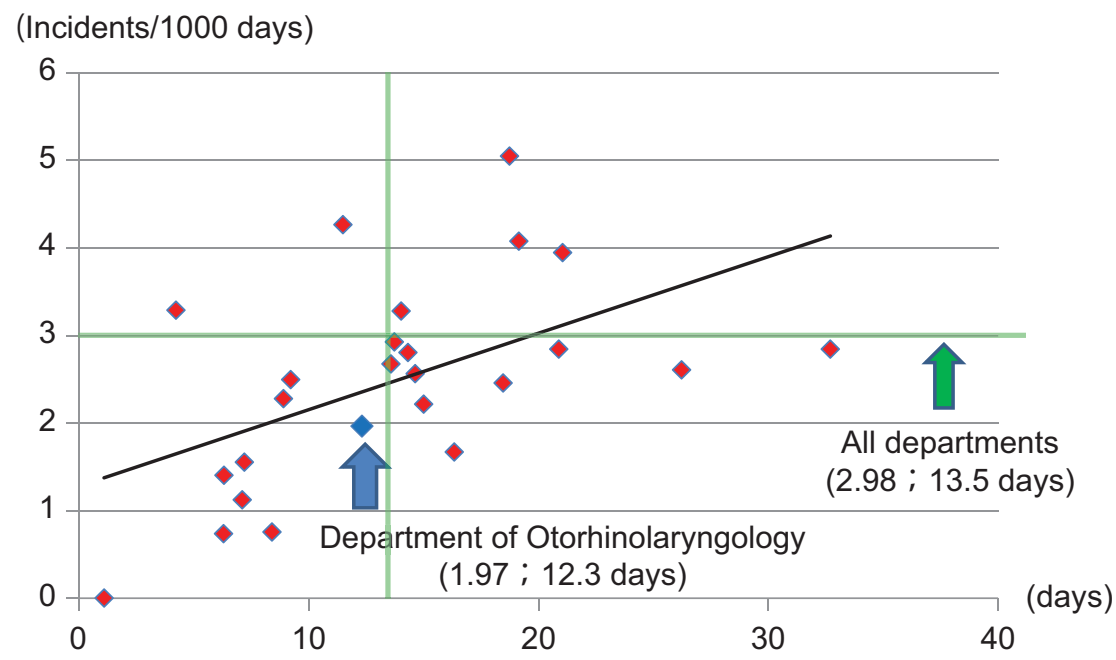

Fig. 5 Fall rate according to department and mean hospital stay (excluding the departments with number of hospitalization cases of $\leq 100$ and the emergency department). The red dots show each department, and the blue dots show the Department of Otorhinolaryngology (1.97; 12.3 days). The green line shows the mean of all departments $(2.98 ; 13.5$ days). A linear correlation was observed between the fall rate of each department and the mean hospital stay $\left(y=0.0873 x+1.2793, R^{2}=0.2809\right)$. In the Department of Otorhinolaryngology, both the fall rate and the mean hospital stay were lower than the mean values of all departments.

In terms of age, old age is associated with decreased muscle strength and imbalance, ${ }^{12}$ which can be listed as reasons for falls.

As a countermeasure against falls for patients whose hospitalization is expected to be long, the high risk of falls should be informed to the patient, family, and hospital staff (physicians and nurses) at the beginning of hospitalization. Other possible measures include attempting to break down the hospitalization into multiple segments for treatment.

Severity (if malignant, "stage") and performance status are thought to prolong hospital stay. Therefore, we hope to investigate these items as fall risk factors in the future. We would also like to verify to what extent the assessment scores currently used at our hospital reflect fall risk and to utilize the findings of such verification in future countermeasures against falls.

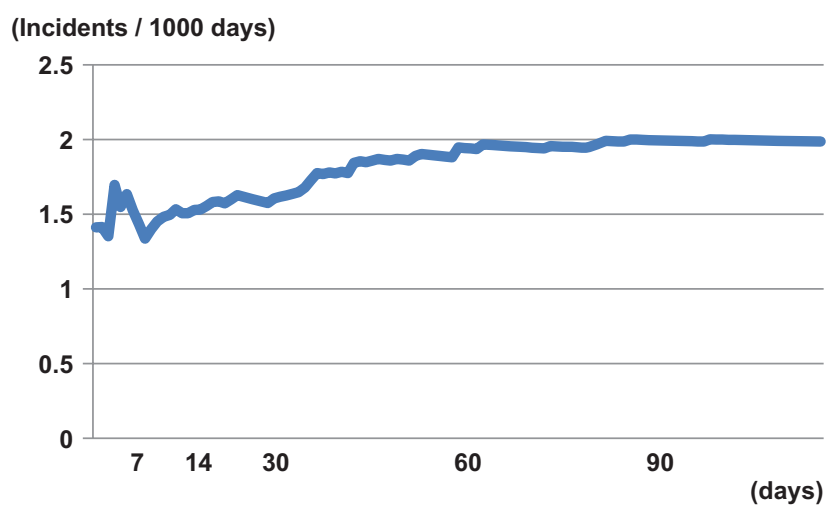

Fig. 6 Hospital stay and fall rate at the Department of Otorhinolaryngology. This shows the fall rate for patients who were hospitalized until day $X$. There was a peak at hospitalization day 4 and the value became lowest on hospitalization day 9 . Thereafter, the fall rate gradually rose as the hospital stay prolonged. This indicates that patients have a greater tendency to fall as the hospital stay becomes longer.
Table 1 Fall rate by disease in the Department of Otorhinolaryngology

\begin{tabular}{|l|l|l|l|}
\hline $\begin{array}{l}\text { Disease } \\
\text { group }\end{array}$ & $\begin{array}{l}\text { Number } \\
\text { of fall } \\
\text { incidents }\end{array}$ & $\begin{array}{l}\text { Total days } \\
\text { of hospital } \\
\text { stay (d) }\end{array}$ & $\begin{array}{l}\text { Fall } \\
\text { rate }\end{array}$ \\
\hline $\begin{array}{l}\text { Malignant } \\
\text { disease }\end{array}$ & 76 & 26.089 & 2.91 \\
\hline $\begin{array}{l}\text { Ear disease } \\
\text { (excluding } \\
\text { malignant) }\end{array}$ & 18 & 13.820 & 1.30 \\
\hline $\begin{array}{l}\text { Nose disease } \\
\text { (excluding } \\
\text { malignant) }\end{array}$ & 6 & 5.015 & 1.20 \\
\hline $\begin{array}{l}\text { Other benign } \\
\text { diseases }\end{array}$ & 20 & 16.141 & 1.24 \\
\hline
\end{tabular}

Notes: The fall rate for malignant disease patients was significantly higher than those with ear and other diseases ( $p=0.0045, p=0.0019$; comparison of four groups with Fisher's exact test and Benjamini-Hochberg procedure).

Table 2 Fall rate by treatment for malignant otorhinolaryngological diseases

\begin{tabular}{|l|l|l|l|l|}
\hline Treatment & $\begin{array}{l}\text { Yes/ } \\
\text { No }\end{array}$ & $\begin{array}{l}\text { Number of } \\
\text { hospitaliza- } \\
\text { tions }\end{array}$ & $\begin{array}{l}\text { Fall } \\
\text { rate }\end{array}$ & $p$-Value \\
\hline \multirow{2}{*}{ Surgery } & + & 552 & 2.42 & \multirow{2}{*}{$p=0.161$} \\
\cline { 2 - 4 } & - & 484 & 3.36 & \\
\hline \multirow{2}{*}{ Chemotherapy } & + & 460 & 2.37 & $p=0.053$ \\
\cline { 2 - 4 } & - & 576 & 3.68 & \\
\hline \multirow{2}{*}{ Radiotherapy } & + & 168 & 3.34 & \multirow{2}{*}{$p=0.295$} \\
\cline { 2 - 4 } & - & 868 & 2.63 & \\
\hline
\end{tabular}

Notes: The fall rates are shown depending on whether surgery, chemotherapy, and radiotherapy were performed. The comparisons did not reveal any significant differences ( $p>0.05$; chi-square test). 
Table 3 Whether falls occurred during one hospitalization (univariate analysis)

\begin{tabular}{|l|l|l|l|l|}
\hline & & $\begin{array}{l}\text { Fall } \\
\text { occurrence } \\
\text { (incidents) }\end{array}$ & $\begin{array}{l}\text { No fall } \\
\text { (incidents) }\end{array}$ & -Value \\
\hline Age $\geq 65 \mathrm{y}$ & + & 62 & 1,759 & $p<0.0001$ \\
\cline { 2 - 4 } & - & 23 & 3,116 & \\
\hline $\begin{array}{l}\text { Malignant } \\
\text { disease }\end{array}$ & + & 49 & 987 & $p<0.0001$ \\
\cline { 2 - 4 } & - & 36 & 3,888 & \\
\hline \multirow{2}{*}{ Sex: male } & + & 56 & 2,841 & $p=0.158$ \\
\cline { 2 - 4 } & - & 29 & 2,034 & \\
\hline \multirow{2}{*}{$\begin{array}{l}\text { Hospital stay } \\
\geq 14 \mathrm{~d}\end{array}$} & + & 54 & 816 & $p<0.0001$ \\
\cline { 2 - 4 } & - & 31 & 4,059 & \\
\hline
\end{tabular}

Notes: We compared whether falls occurred in individual patients depending on the four factors: 65 years or older, malignant disease, male sex, and hospital stay of $\geq 14$ days. Univariate analysis indicated that age $\geq 65$ years, malignant disease, and hospital stay of $\geq 14$ days were significantly correlated to propensity for falls.

Table 4 Number of falls per hospitalization (multivariate analysis)

\begin{tabular}{|l|l|l|l|l|}
\hline & \multirow{2}{*}{$\begin{array}{l}\text { Odds } \\
\text { ratio }\end{array}$} & \multicolumn{2}{|l|}{$\begin{array}{l}\text { (95\% confidence } \\
\text { interval) }\end{array}$} & \multirow{2}{*}{-Value } \\
\cline { 3 - 4 } & & $\begin{array}{l}\text { Minimum } \\
\text { value }\end{array}$ & $\begin{array}{l}\text { Maximum } \\
\text { value }\end{array}$ & \\
\hline Age $\geq 65$ y & 3.05 & 1.850 & 5.040 & $p<0.0001$ \\
\hline $\begin{array}{l}\text { Malignant } \\
\text { disease }\end{array}$ & 1.61 & 0.948 & 2.740 & $p=0.0779$ \\
\hline Sex: male & 1.11 & 0.697 & 1.770 & $p=0.657$ \\
\hline $\begin{array}{l}\text { Hospital } \\
\text { stay } \geq 14 \mathrm{~d}\end{array}$ & 5.21 & 3.060 & 8.870 & $p<0.0001$ \\
\hline
\end{tabular}

Note: Multivariate analysis indicated significant differences for the two factors of being $\geq 65$ years and hospital stay of $\geq 14$ days.

Table 5 Number of male and female inpatients in our hospital and the mean age (all departments, Department of Otorhinolaryngology)

\begin{tabular}{|l|l|l|l|}
\hline \multicolumn{2}{|c|}{} & $\begin{array}{l}\text { Number of } \\
\text { discharged } \\
\text { patients } \\
\text { (people) }\end{array}$ & $\begin{array}{l}\text { Mean } \\
\text { age }(y)\end{array}$ \\
\hline \multirow{2}{*}{ All departments } & Total & 132.041 & 59.0 \\
\cline { 2 - 4 } & Male & 67.433 & 60.3 \\
\cline { 2 - 4 } & Female & 64.608 & 57.6 \\
\hline \multirow{2}{*}{$\begin{array}{l}\text { Department of } \\
\text { Otorhinolaryn- } \\
\text { gology }\end{array}$} & Total & 4.960 & 51.4 \\
\cline { 2 - 4 } & Male & 2.897 & 51.3 \\
\cline { 2 - 4 } & Female & 2.063 & 51.6 \\
\hline
\end{tabular}

Notes: While males accounted for $51 \%$ of inpatients in all departments, they accounted for a higher percentage (58\%) of inpatients in the Department of Otorhinolaryngology. While female patients were younger than male patients by 2.7 years in all departments, hardly any difference (0.3 years) was observed for the Department of Otorhinolaryngology.

\section{Conclusion}

Falls are important in-hospital incidents/accidents requiring countermeasures. Actions before and after excretion are a common fall-onset mechanism found in patients across all departments, and common underlying factors for falls in the Department of Otorhinolaryngology are the use of medication, such as sleeping pills, and gait disturbance. In the Department of Otorhinolaryngology, the three parameters-age, malignant disease, and duration of hospital stay-are factors affecting fall frequency, and duration of hospital stay and age need to be viewed with greater importance. In particular, proactive attempts should be made to reduce fall risk in elderly patients who have or are likely to have a prolonged hospital stay.

\section{Conflicts of Interest}

None.

\section{Acknowledgments}

We thank the Medical Affairs Section, Medical Safe Section, and Medical Information Section of Wakayama Red Cross Medical Center for their cooperation.

\section{References}

1 Egami K, Hirose M, Tsuda Y, et al. Clinico-epidemiological aspect of fall cases in clinical training hospitals based on incident reports. J Japan Soc Healthcare Admin 2012;49:205-215

2 Kamiuchi T. Results of past 10 years for fall prevention amongst elderly. Initiatives over past 10 years and future challenges for preventing falls amongst elderly in healthcare facilities. Japanese J Phys Therap 2010;27:638-644

3 Ozaki M, Miki K. Survey on falls amongst elderly at Hospital A - based on incident and accident reports. Nurs J Hiroshima Int Univ 2006; 3:41-46

4 Sonoda T, Harada T. Examining approach for general practitioners! Frequent events and incidents for prevention. Drug adverse reaction case file (No. 3): Falls. Multilateral evaluation including drug characteristics. Med Drug J 2017;59:770-780

5 Hagino $\mathrm{H}$. Advances in insomnia treatment for elderly-prevention and treatment. Elderly fall prevention. Countermeasures and involvement of insomnia and sleeping pills. Geriatr Med 2015; 53:1089-1093

6 Kasai T, Watanabe T, Tanaka E, et al. Relationship between elderly self-evaluation of physical strength and fall risk 15 years later. Japanese J Human Sci Health Soc Serv 2015;22:33-44

7 Masumoto T, Yamada Y, Yamada M, et al. [Fall risk factors and sex differences among community-dwelling elderly individuals in Japan. A Kameoka study]. Nippon Koshu Eisei Zasshi 2015;62(08):390-401

8 Kato R, Takagi C, Sakurai N, Hoshi T. [Risk factors for falls and survival after falling in elderly people in a community]. Nippon Koshu Eisei Zasshi 2012;59(05):305-314

9 Morioka S, Miyamoto K, Takebayashi H, et al. Process of change in standing balance ability and ability to discern two points on the sole of the foot by age. Japanese J Phys Therap 2005;39:919-926

10 NARI (National Ageing and Research Institute). An analysis of research on preventing falls and falls injury in older people: community, residential care and hospital settings (2004 update). Australian Government, Department of Health and Aging, Injury Prevention Section; 2004

11 Ogawa A. Dementia countermeasures-results of multidisciplinary initiatives. Response to dementia at acute hospitals. Basic Hosp Policy 2016;7:11-16

12 Kaneko K. Sports and health-what is locomotive syndrome? Juntendo Med J 2011;57:449-455 